\title{
PENGARUH SALES PROMOSION DAN PERSONAL SELLING TERHADAP KEPUTUSAN PEMBELIAN PADA UD. CIPTA KARYA ABADI LAMONGAN
}

\author{
Rahayu Mufiyati', Nawari ${ }^{2}$ \\ Fakultas Ekonomi Universitas Islam Darul 'Ulum Lamongan \\ E-mail : rahayu.mufiyati@gmail.com \\ E-mail : nawari@unisda.ac.id
}

\begin{abstract}
UD. Cipta Karya abadi is a company engaged in trading household appliances. Its flagship product is the multipurpose pot CKA POT. Using special and unique concepts in the sales activities of superior products, namely by direct sales, by conducting promotions, introducing products and even directly practicing cooking demonstrations in front of prospective customers. The purpose of this research is to find out the effect of Sales Promotion and Personal Selling partially or simultaneously on Purchasing Decisions. The number of samples in this study were 98 respondents. While the sampling technique used in this study was simple random sampling technique. The data is analyzed using the SPSS program, Variable Sales Risk $(X 1)=0,000<0,05$, Personal Selling Variable $(X 2)=0,000<0,05$. From the equation above the variable significance of the price is smaller than 0.05, the significance of the Sales Promosion variable is smaller than 0.005 and the significance of the small Personal Selling variable is greater than 0.05, then the X1 variable has a positive effect on $Y$ and $X 2$ has a positive effect on variable $Y$.
\end{abstract}

Keywords: Sales Promotion, Personal Selling, Purchasing Decisions

ABSTRAK: UD. Cipta Karya abadi merupakan perusahaan yang bergerak dibidang perdagangan alat-alat rumah tangga. Produk unggulannya yaitu panci serba guna CKA POT. Mengunkan konsep khusus dan unik dalam aktivitas penjualan produk-produk unggulannya, yakni dengan penjualan langsung, dengan cara melakukan promosi, memperkenalkan produk bahkan langsung praktek demo masak dihadapan calon konsumen. Tujuan dalam penelitian ini adalah untuk mengetahui Pengaruh Sales Promosion dan Personal Selling secara parsial maupun secara simultan terhadap Keputusan Pembelian. Jumlah sampel dalam penelitian ini sebanyak 98 responden. Sedangkan teknik pengambilan sampel yang digunakan dalam penelitian ini adalah teknik accidental sampling. Data di analisis dengan menggunakan program SPSS, Variabel Sales Pomosion $(X 1)=0,000<0,05$, Variabel Personal Selling $(X 2)=0,000<0,05$. Dari persamaan diatas signifikansi variabel harga lebih kecil dari 0,05, signifikansi variabel Sales Promosion lebih kecil dari 0,005 dan signifikansi variabel Personal Selling kecil besar dari 0,05, maka variabel X1 berpengaruh positif terhadap variabel $\mathrm{Y}$ dan variabel $\mathrm{X} 2$ berpengaruh positif terhadap variabel $\mathrm{Y}$.

Kata Kunci : Sales Promosion, Personal Selling, Keputusan Pembelian

\section{PENDAHULUAN}

\section{Latar Belakang}

Perekonomian indonesia telah memasuki era globalisasi, dimana kemajuan teknologi yang semakin pesat dan adanya perdagangan bebas menyebabkan semakin ketatnya persaingan antar bisnis yang ada. Membuat perusahaan semakin dituntut agar bergerak lebih cepat dalam hal menarik konsumen, sehingga perusahaan yang menetapkan konsep pemasaran perlu mencermati perilaku konsumen dan faktor-faktor yang mempengaruhi keputusan pembeliannya. Salah satunya dengan media promosi yang diberikan perusahaan dalam rangka menarik perhatian konsumen untuk melakukan keputusan pembelian.

Pemilihan media promosi yang tepat dan akurat dapat menentukan 
keberhasilan suatu perusahaan dalam memasarkan produknya. Promosi memerlukan lebih dari sekedar perkenalan keunggulan-keuggulan produk, dan harga yang menarik, serta membuatnya dapat terjangkau, akan tetapi kegiatan promosi dimaksutkan untuk dapat melakukan komunikasi dengan konsumen, memperkenalkan, membujuk, mempengaruhi dan mendorong konsumen untuk membeli produk yang ditawarkan.

Sales promosion adalah salah satu kegiatan promosi untuk melakukan rangsangan kepada konsumen untuk melakukan pembelian. Menurut Kotler \& keller (2016: 582) "Sales Promotion adalah insentif jangka pendek untuk mendorong percobaan atau pembelian produk atau layanan termasuk promosi pelanggan”.

Personal Selling merupakan aspek penjualan melalui proses komunikasi person-to-persen. Penerapan personal selling cenderung bervariasi antar perusahaan, tergantung pada sejumlah faktor, seperti karakteristik produk atau jasa yang dipasarkan (Trijono dan Chandra, 2012: 376).

UD Cipta Karya Abadi merupakan distributor panci besar di indonesia yang sudah memiliki berbagai cabang di nusantara yang salah satunya terletak di lamongan. Produk yang diperjual belikan yaitu panci serba guna dengan merek CKA, barang yang dihasilkan merupakan produk sendiri untuk panic pot dan untuk produk panic lainnya dihasilkan melalui impor. Sistem penjualan yang dilakukan dengan tenaga-tenaga sales dan berbagai promosi yang diberikan dalam upaya menarik perhatian konsumen, seperti sales promotion, iklan, door to door dan ke instansi-instansi. Strategi penjualan yang dilakukan dalam UD. Cipta Karya Abadi Lamongan untuk menarik keputusan pembelian konsumen yaitu sales promotion dan personal selling. Sehingga peran tenaga penjual sangat berpengaruh dalam memperkenalkan promosi yang diberikan perusahaan kepada konsumen agar melakukan keputusan pembelian.

\section{Rumusan Masalah}

1. Apakah sales promotion berpengaruh terhadap keputusan pembelian pada UD. Cipta Karya Abadi Lamongan?

2. Apakah personal selling berpengaruh terhadap keputusan pembelian pada UD. Cipta Karya Abadi Lamongan?

3. Apakah sales promotion dan personal selling berpengaruh terhadap keputusan pembelian pada UD. Cipta Karya Abadi Lamongan?

\section{Tujuan Penelitian}

1. Untuk mengetahui pengaruh sales promotion terhadap keputusan pembelian pada UD. Cipta Karya Abadi Lamongan.

2. Untuk mengetahi pengaruh personal selling terhadap keputusan pembelian pada UD. Cipta Karya Abadi Lamongan.

3. Untuk mengetahui apakah pengaruh sales promotion dan personal selling dapat mempengaruhi keputusan pembelian pada UD. Cipta Karya Abadi Lamongan.

\section{TINJAUN PUSTAKA}

\section{a. Sales Promosion}

Sales promotion merupakan salah satu dari bauran promosi atau yang biasa disebut promotion mix. Promotion mix adalah "startegi yang paling baik merupakan dikombinasikan variabel periklanan 
dengan satu atau lebih, personal selling dan alat promosi lainnya yang semuanya direncanakan untuk mencapai tujuan program penjualan“.

Kalau iklan menawarkan alasan untuk membeli, promosi penjualan menawarkan insentif untuk mebeli. Promosi penjualan mencakup alat untuk promosi konsumen (sampel, kupon, tawaran uang kembali, potongan harga, cinderamata, hadiah, hadiah berlangganan, pengujian gratis, garansi, promosi bersama, promosi silang, pajangan di tempat pembeliandan peragaan).

\section{b. Pesonal Selling}

Personal selling merupakan salah satu metode promosi untuk mencapai tujuan penjualan yaitu membantu konsumen melakukan keputusan pembelian. Dalam operasinya personal selling lebih fleksibel di bandingkan dengan yang lain. Sebab tenaga-tenaga penjual tersebut secara langsung mengetahui keinginan motif dan perilaku konsumen dan sekaligus dapat dilihat reaksi konsumen sehingga mereka langsung mengadakan penyesuaian seperlunya.

Menurut Ali Hasan (2013: 604) "Penjualan personal (personal selling) adalah presentasi secara lisan dengan satu atau lebih calon konsumen dengan tujuan melakukan penjualan.

\section{c. Keputusan Pembelian}

Keputusan Pembelian adalah tahapan dimana pembeli telah menentukan pilihannya dan melakukan pembelian produk, serta mengkonsumsinya (Suharno: 2010).
Keputusan pembelian antara satu konsumen dengan yang lainnya berbeda-beda, menurut Schifman dan Kanuk (2008: 485) "Keputusan pembelian adalah seleksi terhadap dua pilihan alternatif atau lebih. Konsumen sebelum memutuskan untuk membeli suatu produk pasti memiliki alternatif sebagai pertimbangan.

\section{d. Kerangka Konseptual}

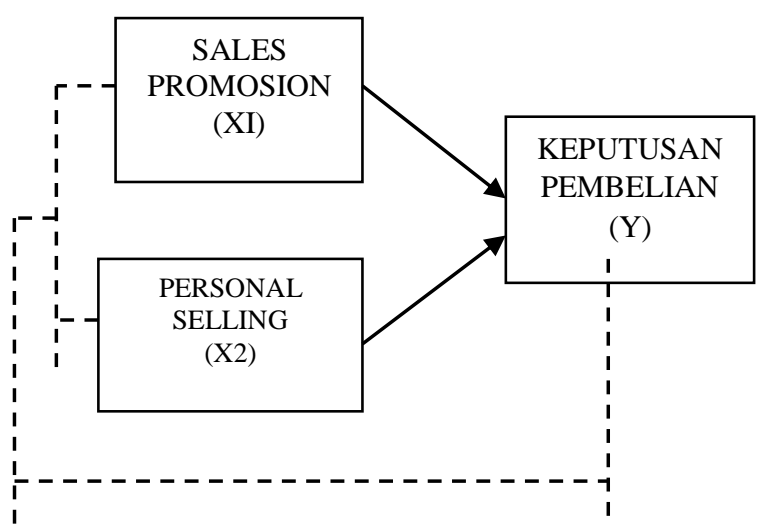

Gambar 2.3.2 Kerangka Konseptual

Keteragan

Parsial

Simultan

\section{e. Hipotesis}

$$
\begin{gathered}
\mathrm{H}_{1}=\quad \text { Sales Promotion } \\
\text { berpengaruh secara signifikan } \\
\text { terhadap keputusan pembelian } \\
\text { pada UD. Cipta Karya Abadi } \\
\text { Cabang Lamongan } \\
\mathrm{H}_{2}=\quad \text { Personal Selling } \\
\text { berpengaruh secara signifikan } \\
\text { terhadap keputusan pembelian }
\end{gathered}
$$


pada UD. Cipta Karya Abadi

Cabang Lamongan

$$
\begin{aligned}
\mathrm{H}_{3}= & \text { Sales Promotion dan } \\
& \text { Personal Selling berpengaruh } \\
& \text { secara bersama sama terhadap } \\
& \text { keputusan pembelian pada UD. } \\
& \text { Cipta Karya Abadi Cabang } \\
& \text { Lamongan }
\end{aligned}
$$

\section{METODE PENELITIAN}

\section{a. Pendekatan Penelitian}

Pendekatan yang digunakan dalam penelitian ini adalah penelitian kuantitatif. Menurut Sugiono (2017: 7) Metode penelitian kuantitatif yaitu metode penelitian yang berlandaskan pada filsafat positifisme,

\section{b. Tempat dan Waktu Penelitian}

Penelitian ini dilakukan di UD. Cipta Karya Abadi Cabang Lamaongan yang terletak di Jl. Raya Rowo Rejo Gang II, No 22, Babat Banaran, kab. Lamongan. Penelitian di lakukan selama 3 bulan bertahap.

\section{c. Objek Penelitian}

Objek penelitian adalah sifat keadaan dari suatu benda, orang atau yang menjadi pusat perhatian dan sasaran penelitian. Sifat keadaan dimaksud bisa berupa sifat, kuantitas dan kualitas yang bisa berupa prilaku, kegiatan, pendapat, pandangan penelitian, sikap pro-kontra, keadaan batin dan bisa juga berupa proses. Objek penelitian yang dikaji adalah sales promotion dan personal selling dalam mempengaruhi keputusan pembelian konsumen pada UD. Cipta Karya Abadi Cabang Lamongan.

\section{d. Populasi, Sampel dan Teknik Pengambilan Sampel}

\section{Populasi}

Menurut Mohammad Hasyim (2012: 130) "Populasi adalah subjek yang akan diperlukan dalam penelitian dan akan diungkap gejala, kejadian ataupun datanya, sehingga akan diperoleh kesimpulan secara general dari pokok masalahnya. Berdasarkan dengan hal ini maka yang menjadi populasi dalam penelitian ini adalah konsumen pada UD. Cipta Karya Abadi pada tahun 2018.

\section{Sampel}

Menurut Jusuf Soewadji (2012:131), Sampel adalah sebagian saja dari seluruh jumlah populasi, yang diambil dari populasi dengan cara yang sedemikian rupa sehingga dapat dianggap mewakili seluruh anggota populasi. Untuk menentukan jumlah sampel dalam penelitian ini menggunakan rumus Slovin (Meutia Dewi, 2015:210):

$$
\begin{gathered}
\mathrm{n}=\frac{\mathrm{N}}{1+\mathrm{Ne}^{2}} \\
\mathrm{n}=\frac{7.760}{1+7.760(0,1)^{2}} \\
\mathbf{n}=\mathbf{9 8}
\end{gathered}
$$

Berdasarkan perhitungan diatas maka diperoleh jumlah sampel yang akan dijadikan responden sebanyak 98 konsumen.

\section{e. Teknik Pengambilan Sampel}

Adapun teknik sampling yang digunakan dalam penelitian ini adalah sampling aksidental (Margono: 2014:126) menyatakan bahwa sampling aksidental adalah 
teknik penentuan sampel berdasarkan spontanitas, artinya siapa saja secara tidak sengaja bertemu peneliti dan sesuai dengan karakteristik (ciri-cirinya), maka orang tersebut dapat digunakan sebagai sampel (responden).

\section{f. Teknik Pengumpulan Data}

1. Observasi, Yaitu metode pengambilan data dengan cara melakukan pengamatan dan pencatatan terhadap fenomena yang diselidiki (Sugiyono, 2013: 203).

2. Wawancara, Yaitu metode pengambilan data dengan melakukan tanya jawab langsung terhadap fenomena yang diselidiki (Sugiono, 2013: 194).

3. Dokumentasi, Yaitu mengumpulkan data dari perusahaan yang berupa dokumen tertulis oleh perusahaan (Sugiono, 2013: 193).

4. Kuisioner, Yaitu merupakan teknik pengumpulan data yang dilakukan dengan cara memberikan seperangkat pertanyaan tertulis kepada responden untuk dijawabnya, dalam penelitian ini kuisioner akan diberikan kepada pelanggan (Sugiono, 2013:199).

\section{g. Metode Analisis Data}

\section{Uji Validitas}

Pengujian ini dilakukan dengan membandingkan $r$ hitung dan $r$ tabel. Nilai $r$ hitung merupakan hasil dari hubungan jawaban responden kepada masingmasing pertanyaan atau pernyataan setiap variabel yang dianalisis dengan program spss dan outputnya. Juga merupaka salah satu alat yang digunakan untuk mengukur valid atau tidak valinya suatu kuesioner. Hasil Suatu kuesioner akan dikatakan valid jika pertanyaan pada kuesioner mampu mengungkapkan dari apa yang akan diukur oleh kuesioner tersebut (Ghozali, 2011:52).

\section{Uji Reabilitas}

Menurut

Sugiyono (2017:354) reliabilitas adalah drajat konsistensi data dalam interval waktu tertentu. Pengujian reliabilitas yaitu membandingkan nilai alpha dengan nilai $\mathrm{r}$ product moment untuk menghasilkan data yang lebih besar dari angka kritis dalam tabel $\mathrm{r}$ product moment maka data tersebut relibel.

\section{Uji Regresi Linier Berganda}

Berdasarkan metode penelitian dan untuk menjawab rumusan masalah yang ada, disini peneliti menggunakan statistik dengan perhitungan regresi linier berganda. Menganalisis dengan menggunakan SPSS yaitu:

$$
Y=a+b_{1} X_{1}+b_{2} X_{2}+e
$$

Dimana:

$\mathrm{Y}=$ Keputusan Pembelian

$\mathrm{a}=$ Konstanta

$b_{1}=$ Koefisien regresi sales

promotion

$\mathrm{b}_{2}=$ Koefisien regresi personal

selling

$\mathrm{X}_{1}=$ Sales promotion

$\mathrm{X}_{2}=$ Personal selling

$\mathrm{e}=$ standar eror

\section{Uji Asumsi Klasik}




\section{a. Uji Heteroskedatistas}

Uji heteroskedastisitas bertujuan untuk menguji suatu model apakah dalam model regresi terjadi ketidaksamaan variance dari residual satu pengamatan ke pengamatan yang lain (Ghozali,

\begin{tabular}{|l|c|c|c|c|}
\hline Item & r Hitung & & r Tabel & \\
\hline X2.1 & 0,757 & $>$ & 0,197 & Valid \\
\hline X2.2 & 0,358 & $>$ & 0,197 & Valid \\
\hline X2.3 & 0,548 & $>$ & 0,197 & Valid \\
\hline X2.4 & 0,610 & $>$ & 0,197 & Valid \\
\hline X2.5 & 0,376 & $>$ & 0,197 & Valid \\
\hline X2.6 & 0,537 & $>$ & 0,197 & Valid \\
\hline X2.7 & 0,447 & $>$ & 0,197 & Valid \\
\hline X2.8 & 0,548 & $>$ & 0,197 & Valid \\
\hline \multicolumn{5}{|c}{ 2009:105). } \\
\hline
\end{tabular}

b. Uji Normalitas

Priyanto

(2011:277)

mengemukakan uju normalitas pada model regresi digunakan untuk menguji apakah nilai residual terdistribusi secara normal atau tidak.

\section{c. Uji Multikolinieritas}

Uji Multikolinearitas bertujuan

\begin{tabular}{|c|c|c|c|c|}
\hline Item & r Hitung & & r Tabel & \\
\hline X1.1 & 0,677 & $>$ & 0,197 & Valid \\
\hline X1.2 & 0,587 & $>$ & 0,197 & Valid \\
\hline X1.3 & 0,802 & $>$ & 0,197 & Valid \\
\hline X1.4 & 0,800 & $>$ & 0,197 & Valid \\
\hline X1.5 & 0,814 & $>$ & 0,197 & Valid \\
\hline X1.6 & 0,814 & $>$ & 0,197 & Valid \\
\hline \multicolumn{5}{|c}{ untuk menguji apakah model }
\end{tabular}
regresi ditemukan adanya korelasi antar variabel bebas (independen). Karena model regresi yang baik seharusnya tidak terjadi korelasi di antara variabel independen $\mathrm{Uji}$ Multikolinieritas dilakukan dengan melihat tolerance value atau dengan menggunakan Variance Inflation (VIF) dari hasil analisis dengan menggunakan SPSS.

\section{Uji Kelayakan Model}

a. Uji F

Uji F digunakan untuk menentukan apakah secara serentak variabel independen mampu menjelaskan variabel dependen dengan baik atau apakah variabel independen mempunyai pengaruh yang signifikan terhadap variabel dependen secara bersama - sama. (Sugiyono, 2012:234).

\section{b. Koefisien Determinasi $\left(\mathbf{R}^{\mathbf{2}}\right)$}

Menurut Ghozali (2016:83) bahwa koefisien determinasi pada intinya mengukur seberapa jauh kemampuan model dalam menerangkan variasi variabel dependen.

\section{Uji Hipotensis}

\section{a. Uji Persial (Uji T)}

Uji $T$ atau ujin koefisien regresi secara persial digunakan untuk mengetahui apakah secara persial variabel independen berpengaruh atau tidak terhadap variabel dependen pengujian menggunakan tingkat signifikan $0,05 \quad(\alpha-0,05)$ jika tingkat signifikansi $\mathrm{t}>0,05$.

\section{HASIL PENELITIAN DAN \\ PEMBAHASAN}

\section{a. Hasil Penelitian}

\section{Uji Validitas}

Uji validitas digunakan untuk mengukur sah atau valid tidaknya suatu kuisioner. Pengujian ini dilakukan dengan membandingkan $r$ hitung dan $r$ tabel.

Tabel Hasil Uji Validitas 


\begin{tabular}{|c|c|c|c|c|}
\hline Item & r Hitung & & r Tabel & \\
\hline Y.1 & 0,925 & $>$ & 0,197 & Valid \\
\hline Y.2 & 0,886 & $>$ & 0,197 & Valid \\
\hline Y.3 & 0,677 & & 0,197 & Valid \\
\hline Y.4 & 0,925 & $>$ & 0,197 & Valid \\
\hline Y.5 & 0,541 & $>$ & 0,197 & Valid \\
\hline Y.6 & 0,925 & $>$ & 0,197 & Valid \\
\hline Y.7 & 0,429 & $>$ & 0,197 & Valid \\
\hline Y.8 & 0,553 & $>$ & 0,197 & Valid \\
\hline
\end{tabular}

Sumber: Data Primer diolah

Dari output diatas dijelaskan bahwa $\mathrm{N}=98$ pada signifikasi $5 \%$ diperoleh 0,197 (r tabel), bulir pertanyaan dikatakan valid jika $r$ hitung $>r$ tabel atau nilai $\mathrm{p}<0,05$.

\section{Uji Reablitas}

Dalam penelitian ini mengunakan cronbach's alpha. Kuisioner dapat dikatakan reliabel jika mempunyai alpha lebih dari 0,60 .

\section{Tabel Hasil Uji Reabilitas Variabel X1, X2,dan Y}

\section{Analisis Regresi Linier Berganda Tabel Hasil Uji Analisis Regresi Linier Berganda}

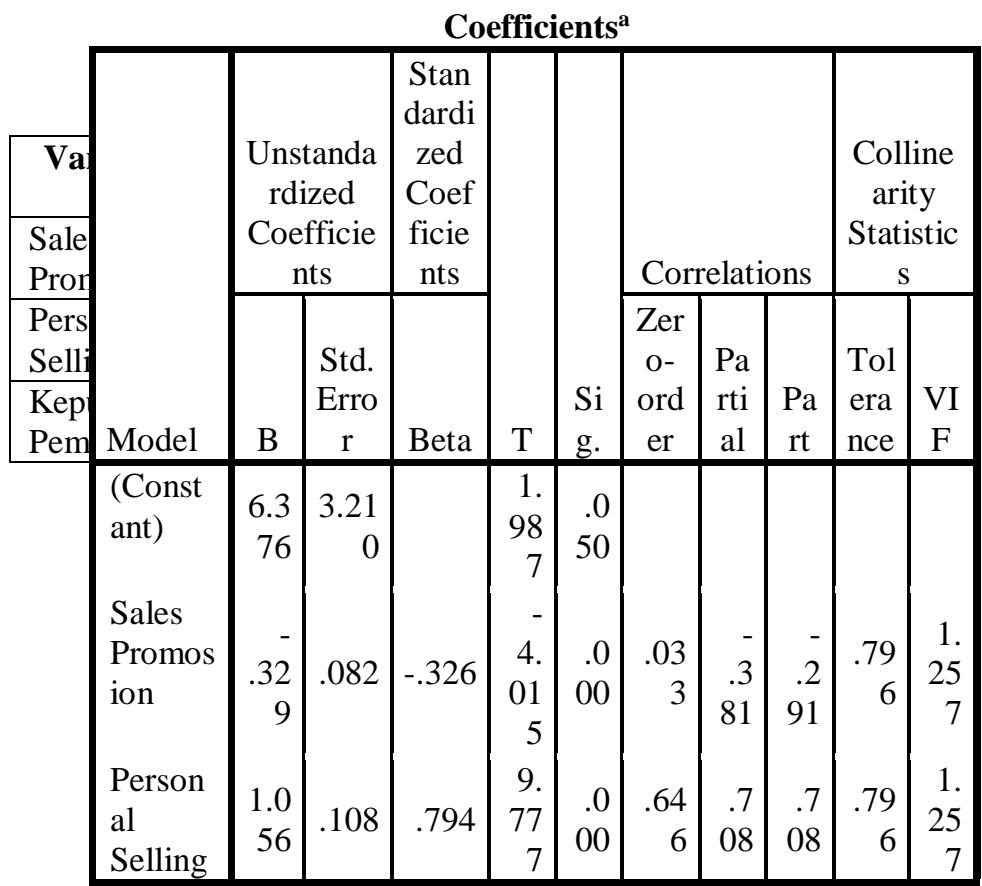

a. Dependent Variable: Keputusan Pembelian Sumber: Data primer diolah

$$
\begin{gathered}
Y=6.376 X_{1}+(-0,329) X_{2}+1.056 \\
\text { Dari persamaan tersebut }
\end{gathered}
$$
diketahui bahwa koefisien regresi Sales promosion (b1) dan personal selling (b2) memiliki koefisien regresi positif. Hal tersebut menunjukkan bahwa Sales Promosion $\left(\mathrm{X}_{1}\right)$ dan Personal selling $\left(\mathrm{X}_{2}\right)$ memiliki pengaruh secara positif terhadap keputusan pembelian (Y).

\section{Uji Asumsi Klasik \\ a. Uji Heteroskedastisitas}




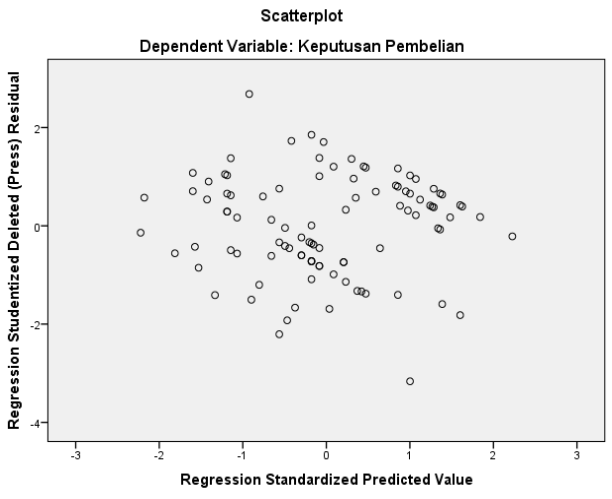

Sumber: Data diolah

Gambar Hasil Uji Heteroskedastisitas Manggunakan SPSS

Dengan melihat tampilan grafik Scaterplot dalam Gambar diatas maka dapat disimpulkan bahwa grafik aceterplot terlihat titik-titik menyebar, maka tidak terjadi atau bebas heteroskedastisitas.

\section{b. Uji Normalitas}

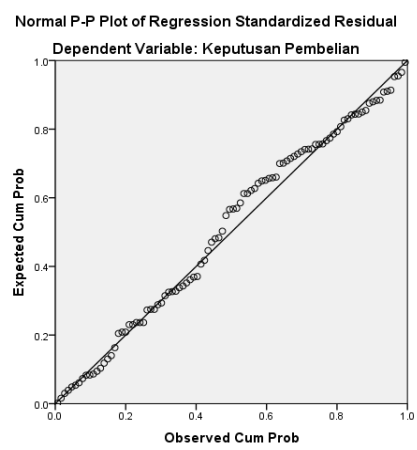

Sumber: Data primer

\section{diolah}

\section{Gambar Hasil Uji Normalitas} Menggunakan Normal P-plot

Dengan melihat tampilan grafik Normal P-plot of Reggresion Startdized Resudal dalam Gambar diatas maka dapat disimpulkan bahwa terlihat titik-titik menyebar disekitar garis diagonal dan tersebut menunjukkan bahwa regresi tidak menyalahi Asumsi Normalitas.

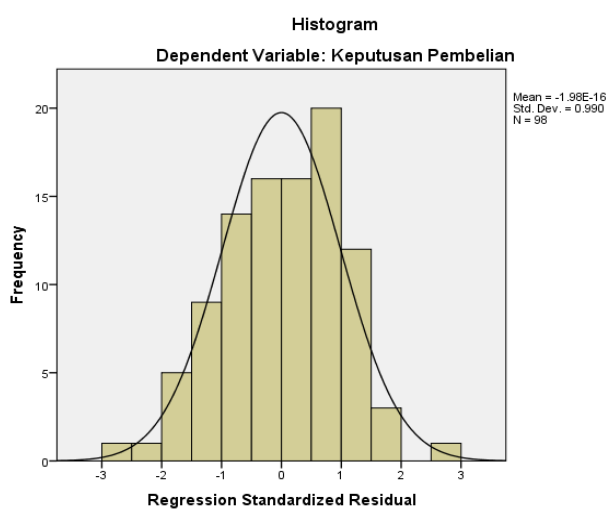

\section{Gambar Hasil Uji Normalitas Menggunakan Histogram}

\section{Sumber : Data diolah}

Dari hasil yang terbentuk grfik histrogram dalam Gambar diatas maka dengan ini dapat diambil kesimpulan bahwa grafik histogram memberikan pola distribusi yang normal dan grafik tersebut menunjukkan bahwa regresi tidak menyalahi Asumsi Normalitas, jadi dapat disimpulkan bahwa model regresi pada penelitian ini memenuhi syarat untuk menjadi model regresi yang baik karena merupakan model regresi yang memiliki distribusi data normal atau mendekati normal.

\author{
c. Multikolinieritas \\ Tabel Hasil Uji Multikolinieritas \\ Coefficients
}




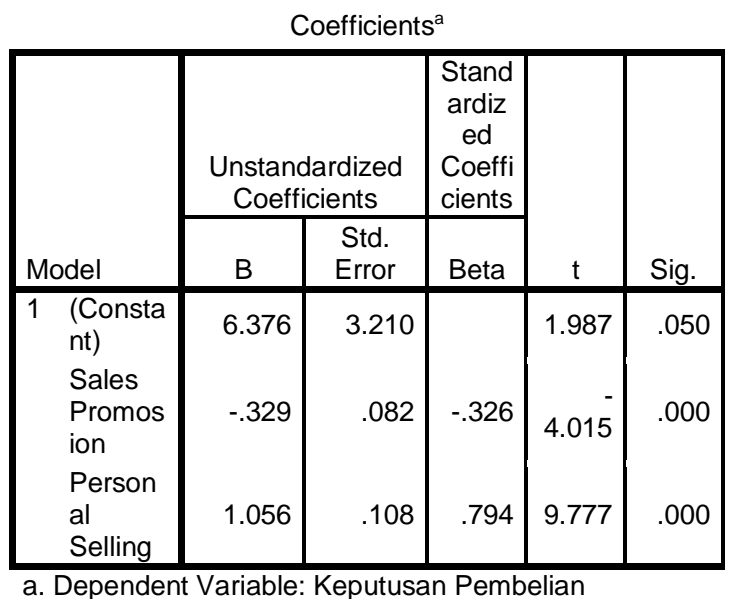

Sumber: Data primer diolah

1. Variabel Sales Promosion $=0,000$ $<0,05$

2. Variabel Personal Selling $=0,000<$ 0,05

Dari $\begin{array}{r}\text { persamaan } \\ \text { variabel }\end{array} \begin{array}{r}\text { diatas } \\ \text { sales }\end{array}$
signifikansi
promosion lebih kecil dari 0,05 dan
signifikansi variabel personal
selling lebih kecil dari 0,005 . Maka
variabel $\mathrm{X}_{1}$ berpengaruh positif
terhadap variabel Y dan variabel $\mathrm{X}_{2}$
berpengaruh positif terhadap
variabel $Y$.

\section{b. Pembahasan}

Penelitian ini bertujuan untuk mengetahui pengaruh sales promosion dan personal selling terhadap keputusan pembelian pada UD. Cipta Karya Abadi Lamongan. Berikut ini penjelasan atas jawaban dari hipotesis penelitian.

Hasil penelitian menunjukkan bahwa pengaruh sales promosion berpengaruh positif dan signifikan terhadap keputusan pembelian pada UD. Cipta Karya Abadi Lamongan. Hal ini dibuktikan dengan nilai signifikasi 0,000 dengan mengunakan batas nilai signifikan 0,05 , nilai signifikan tersebut lebih lebih kecil dari 0,05 yang berarti bahwa sales promosion berpengaruh positif dan signifikan terhadap keputusan pembelian pada UD. Cipta Karya Abadi Lamongan.

Hasil penelitian menunjukkan bahwa pengaruh personal selling berpengaruh positif tan signifikan terhadap keputusan pembelian pada UD. Cipta Karya Abadi Lamongan. Hal ini dibuktikan dengan nilai signifikasi 0,000 dengan mengunakan batas nilai signifikan 0,05 , nilai signifikan tersebut lebih lebih kecil dari 0,05 yang berarti bahwa personal.

\section{SIMPULAN DAN SARAN}

\section{Simpulan}

Berdasarkan hasil penelitian dan pembahasan yang telah dikemukakan oleh penulis diatas, maka dapat ditarik beberapa kesimpulan sebagai berikut :

1) Variabel sales promosion berpengaruh positif terhadap keputusan pembelian pada UD. Cipta Karya Abadi lamaongan. Hal ini dibuktikan dari nilai signifansi 0,000 lebih kecil dari 0,05 $(0,000<0,05)$.

2) Variabel personal selling berpengaruh positif terhadap keputusan pembelian pada UD. Cipta Karya Abadi lmaongan. Hal ini dibuktikan dari nilai signifansi 0,000 lebih kecil dari 0,05 $(0,000<0,05)$.

3) Variabel sales promosion dan personal selling berpengaruh positif terhadap keputusan pembelian pada UD. Cipta Karya Abadi lmaongan. Hal ini dibuktikan dari nilai signifansi 
0,000 lebih kecil dari 0,05 $(0,000<0,05)$.

\section{Saran}

Sebagai alat ukur dari pembahasan skripsi ini penulis dapat menyampaikan saran dengan harapan :

1) Bagi UD. Cipta Karya Abadi lamongan

Dari hasil penelitian yang dilakukan, variabel yang paling dominan dalam mempengaruhi keputusan pembelian adalah personal selling. Diharapkan bagi pihak UD. Cipta Karya Abadi lamongan untuk tetap mempertahankan kualitas tenaga penjualanya karena hal tersebut memiliki pengaruh terhadap keputusan pembelian kosumen. Upaya yang sebaiknya dilakukan oleh perusahaan UD. Cipta Karya Abadi lmaongan adalah meningkatkan kualitas produk dan meningkatkan promosi penjualannya agar dapat menciptakan keputusan pembelian konsumen.

2) Peneliti Selanjutnya

Untuk melengkapi hasil penelitian ini, sebaiknya penelitian serupa dengan sampel dan obyek yang berbeda agar memperoleh kesimpulan yang lebih lengkap dan dapat dipertanggung jawabkan.

\section{DAFTAR PUSTAKA}

Ade Candra Gunawan dan Febsri Susanti (2017). Pengaruh Bauran Pemasaran dan Harga Terhadap
Keputusan Pembelian Produk Kosmetik Maybelline di Kota Padang, Jurnal Ilmu Ekonomi KBP, Edisi 2017.

Afaful Umah (2018). Pengaruh Advertising, Sales Promosion, Personal Selling, dan Publikasi Terhadap Minat Nasabah Dalam Mengajukan Pembiayaan KPR IB Muamalah DI Bank Muamalah KC Surabaya. Skripsi. Fakultas Ekonomi, Universitas Islam Sunan Ampel.

Bori Damayanto dan Lili Andriani (2018). Pengauh Personal Selling terhadap Keputusan Pembelian Produk, Jurnal Economic Education, Vol 2 No. 1 Edisi April 2018

Denta Purnama (2015). Pengaruh Personal Selling dan Sales Promosion Terhadap Keputusan Pembelian Laptop Lenovo di IT Galeri, Jurnal Manajemen Pemasaran, Edisi 30 Oktober 2018.

Dian Yudhiarka dan Jony Oktavian Haryanto (2012). Pengaruh Personal Selling, Display, Promosi Penjualan Terhadap Kesadaran Merek dan Intensi Membeli Pada Produk Kecantikan Pond,s, Jurnal Ekonomi Bisnis, Vol.17 No.2, Edisi Agustus 2012.

Jusuf Soewadji (2012). Pengantar metodelogi penelitian. Mitra Wacana Media, Jakarta.

Kris Dipayanti (2018). Pengaruh Periklanan Sales Promosion Personal Selling dan Publicity Terhadap Keputusan PembelianProduk Aksesoris Mobil (Study Kasus Kilat Service Medan). Jurnal SMART, Vol.1 No. 48-52. 
Moh. Azus Shony Azar dan Pudyartono (2019). Modul SPSS, Fakultas Ekonomi, Universitas Islam Draul'ulum Lamongan.

Novia Kusuma dan Yuliani Rachma (2018). Personal Selling sebagai Startegi Marketing Layanan Digital ICT, Jurnal Komunikasi dan Bisnis, Vol 5 No. 1 Edisi Maret 2018.

Philip Kotler dan Kavin Lane Keller (2012). Manajemen pemasaran, Jilid 12, Edisi 2. PT Indeks, Jakarta.

Rizky Ageng Kurniasih (2018). Pengaruh Sales Promotion Media Instagram WARDAH Beauty House Surabaya terhadap Keputusan Pembelian Konsumen, Skripsi, Fakultas Dakwah dan Komunikasi, Universitas Islam Negeri Sunan Ampel, Surabaya.

Sugiono (2017). Metode Penelitian Kuantitatif, Kualitatif, Dan $R \& D$, Cetakan kedua puluh lima. Alfabeta, Bandung.

Silvia Sofyan (2017). Pengaruh Periklanan, Sales Promosion, Personal Selling dan Publicity Terhadap Keputusan Pembelian Produk Aksesoris Mobil (Study Kasus Kilat Service Medan), Jurnal SMART, Vol.1 No.1 : 4852, 2017. 